\title{
Learning or Memorization: Self-Directed Medical School Curriculum and the Dangers of Overemphasizing Student Selected Ancillary Resources
}

\author{
Thomas C. Varkey ${ }^{1,2,3^{*}}$ (D), Zachary I. Merhavy ${ }^{4}$, Rhonda M. J. Varkey ${ }^{5}$ (D) Jack B. Ding ${ }^{6}$ (D), \\ John A. Varkey ${ }^{7}$ iD
}

\begin{abstract}
This article is a response to an opinion article, authored by $\mathrm{Wu} \mathrm{JH}$ et al. and published in JAMA 2021 , vol 326 (20) which suggested that the pre-clinical (first two) years of medical school curriculum should revolve around "high-yield" resources as the dominant teaching tool. The article posited that this highly controversial view was the best way to engage with students and was published in a well-read and utilized medical journal. Due to the growing divide between learning resources provided by medical schools and outside resources actually utilized by students, the conclusions drawn in the mentioned opinion article were understandable but interpreted in the wrong vein. Herein, the authors review landmark changes in medical education over the last century and the underpinning rationale to preface their examination of the suggested changes from the mentioned opinion article. The authors conclude with recommendations from a student perspective and a continuation of the last 100 years of advancements.

Keywords

Medical Students; Curriculum; Education

${ }^{1}$ Dell Medical School, The University of Texas at Austin, Austin, Texas, USA

${ }^{2}$ Colangelo College of Business, Grand Canyon University, Phoenix, Arizona, USA

${ }^{3}$ College of Education, The University of Texas at Austin, Austin, Texas, USA

${ }^{4}$ Ross University School of Medicine, Bridgetown, Barbados, USA

${ }^{5}$ No Current Academic Affiliation, USA

${ }^{6}$ Adelaide Medical School, The University of Adelaide, Adelaide, South Australia, Australia

${ }^{7}$ College of Engineering, The University of Notre Dame, Notre Dame, Indiana, USA

*Corresponding author: tvarkey@utexas.edu
\end{abstract}

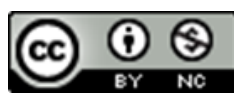

Copyright @Thomas C. Varkey, Zachary I. Merhavy, Rhonda M. J. Varkey, Jack B. Ding, John A. Varkey, 2022

\section{Introduction}

Since the standardization of medical education in the United States in the early $20^{\text {th }}$ century, there has been a constant cycle of innovation and change in pursuit of continually shifting best practices and academic culture. The landmark Flexner Report [1] was responsible for the initial wave of medical education reform and was the direct result of poor standardization of medical education in the preceding years. This reform converged the previously heterogenous set of medical education structures and systems under a common structure, with the most obvious requirement being the need for four years of college education prior to attending four years of medical school. Beginning in early 2020, a new wave in medical education reform and changes in best practice was triggered by the COVID-19 pandemic. This ne- cessitated the movement of students away from traditional in-person lecture points towards online learning modalities that facilitate social distancing. With the COVID-19 pandemic end date being uncertain, and continued profound advancements in online medical learning, there are questions as to how medical education should move forward. This article discusses historical views of medical education and examines several of the changes seen as a direct result of the digital age and COVID-19 in response to a recent opinion article, authored by $\mathrm{Wu} \mathrm{JH}$ et al. and published in JAMA 2021, vol 326 (20) [2].

\section{Historical Views}

The 1910 Flexner Report emphasized the standardization of medical education [1]. This involved the requirement of a 4- 
year bachelor's degree as a prerequisite to entering medical school, followed by several years of medical school education, that encompassed basic science teaching and clinical rotations, to ensure that students were able to engage properly with both the scientific basis of medicine, as well as the subjective and psychological needs of patients themselves [3]. This reform stemmed from the prevailing belief of the time that medical students lacked comprehensive exposure to the full spectrum of medical knowledge and practice. Notably, however, mastering a standardized exam was not part of the initial recommendations of the Flexner Report. Instead, it centralized on the introduction of students to practice medicine safely and carefully on real, living human beings through increased emphasis on the applications of the basic sciences [3]. The overarching aim of implementing teaching of a more scientific basis for medical practice was to ensure that the student would be more prepared to care for patients with the emergence of newer technologies and scientific breakthroughs. This focus on the mastery of the new and emerging science was bolstered with the inclusion of the requirements of a residency program to practice medicine properly in the continental United States in 1889 [4]. These changes to medicine have always placed the most important need, quality, timely, and scientifically backed care of patients with heavy emphasis on their wellbeing and care first.

\section{Changes with the Digital Age}

Since the inception of the Internet, medical schools have incorporated virtual elements into their teaching structures. From the very beginning, however, online platforms have typically been used supplementarily to in-person-based curriculums. Again, during this addition of the Internet, the focus remained not on the ability of students to master a standardized test or ability to follow a checklist to hit a minimum number of skills accomplished in a set period of time, but instead on their ability to safely and carefully practice medicine on real, living human beings [5]. This took the form of caution with moving the United States Medical Licensing Examination (USMLE) to a computerized version and the careful addition of the virtual classroom into medical education.

In the late 1980s and early 1990s, many of the old correspondence courses began to move to the new online platform, with organizations such as the Western Behavioral Sciences Institute and the University of Phoenix leading the charge for the adoption of online schooling for undergraduate and graduate education [6]. These courses often utilized discussion boards, online testing platforms for exam proctoring, homework systems like that of Pearson's "MyLab" for homework assignments and increased reflective essay assignments to ensure that students were able to demonstrate that they were learning while taking part in the online course work [7]. Much of the online platforms continued to change and adapt to the needs of students right up until the beginnings of the COVID-19 pandemic, with very few medical education courses being taught virtually due to many different barriers [8].

At the end of the $20^{\text {th }}$ century and beginning of the $21^{\text {st }}$ century, the mass adoption of the Internet enabled rapid access to files and webpages, which ensured a new ease of accessing raw information [9]. Medical bodies leveraged this new ability, with a major example being the caution of computerizing the USMLE for fear that it would hurt the validity and utility of the examination. Through vigilance, this was avoided and instead the efforts brought many benefits to the examiners $[10,11]$. This, along with the inclusion of a clinical skill examination, were chosen to enable medical students to engage in the diagnosis and treatment of patients safely and properly [5]. Some of the benefits of the Internet and its mass adoption have included the opening of new avenues for increasing access for medical students to instructors through Massive Open Online Courses (MOOCs), virtual case conferences like that of the National Multiple Sclerosis Society's (NMSS) Difficult Case Webinar [12], and virtual grand rounds.

\section{Forced Changes as a Result of COVID-19}

During the first quarter of the calendar year 2020, as a direct result of the COVID-19 pandemic, millions of students were forcibly transitioned from in-class instruction to online programs [13-15]. The educational modality and regularity of meeting varied from institution to institution - ranging from completely asynchronous virtual classrooms to completely synchronous classrooms where students would meet utilizing pre-determined meeting times and video call platforms such as Zoom ${ }^{\circledR}$. Due to the rapid transition to the virtual classroom, many instructors, students, and parents were forced to learn how to engage with the class materials online without much notice.

Medical students continued their education throughout the pandemic either virtually or in a blended classroom with clinical instructions being significantly limited [1621]. Many students subjectively reported that they felt as though their clinical knowledge and experience were greatly diminished as compared to their counterparts who were able to attend in-person lectures, have clinical experiences, and face-to-face conversations with staff, faculty, standardized patients, and real patients in low-stakes clinical settings such as student-run clinics [16-21]. Much of the educational cementing that their counterparts had encountered had a physical connection with the knowledge that they had gained through reading, listening to lectures, answering practice questions, and having conversations with colleagues [16-21]. This direct patient connection to the knowledge gained from didactic learning and conversations with peers and faculty has been cited by many students as the key to both their learning and the excellence demonstrated in the patient rooms during the clinical years [16-21].

\section{Response to JAMA Article}

In the aforementioned opinion article [2], the authors make the claim that there has been a decrease in the number of students attending lectures and engaging with the standard curriculum at different medical institutions. They go on to 
suggest that instead of continuing to utilize the standard curriculum at these institutions, the departments of medical education should instead incorporate student-developed didactic resources [2]. While this sounds appealing, there are five key thoughts that are lost when focusing only on the attendance rates of lectures in relation to how students utilize school-based resources versus that of the "High Yield" resources.

1. The Medical student-driven curriculum that is referred to is based only on the Step 1 USMLE, meaning that it does not include the latest and most advanced research for patient care, but instead is only focused on what is tested on the Step 1 USMLE.

2. The focus is on a standardized examination, not on patient care, meaning that the efforts of the Flexner Report and the caution of the digital age have been thrown to the wayside.

3. These resources do not work to ensure that students actually understand the material, but instead focus only on the student's ability to either memorize information or know "buzzwords" to ensure a higher score on the Step 1 USMLE or other standardized tests. Many of these resources even claim to increase the score that a student will achieve.

4. As with the other movements, the next steps for changes in medical education should be focused on improving scientific literacy, patient care, and finally, ensuring that the students are razor-focused on being the best clinicians that they can be.

5. This does not mean that the resources such as Sketchy, Anki, or First Aid are not useful as adjunctive materials, but instead that they should only be utilized as ancillary ones with suggestions of specific resources to help students retain long-term information for future use.

It is the strongest moral conviction of the authorial team that requiring students to pay hundreds of thousands of dollars in tuition for self-study is inappropriate and indicative of a lack of understanding the goals of medical education as set in the original 1910 Flexner Report [1]. It is the hope of the authorial team that these points help refocus the responsibility of medical educators as facilitators and teachers first and foremost. The recommendation of the authorial team is to either decrease the costs of medical education to appropriately and proportionally reflect the teaching and recommended resources provided to students or to refocus the basic science years to incorporate more clinical pearls to increase student foundational knowledge. Through providing thorough educational materials and classroom time, with focus on the practical and applicable scientific knowledge for patient care, the efforts of the current medical educational system can increase student knowledge guiding towards a growth in overall medical knowledge, not just standardized examination proficiency.

\section{Conclusions}

While recent movements of medical students from attending lectures towards more self-directed learning may be misinterpreted to suggest that the best option is to increas- ingly lean on the shadow curriculum utilized by medical students as adjunctive learning materials, the current lectures utilized in teaching medical students should be modified to encourage attendance by increasing the amount of useful clinical pearls and hints on how best to understand the material, and, finally, provide practice problems or other self-directed testing methodology to both increase student learning and retention. This type of action and the inclusion of utility helps with setting the foundational knowledge necessary to properly engage within the course materials, both for standardized testing and clinical practice.

\section{Ethical Statement}

All Ethical Standards were followed and no human or animal experimentations were performed.

\section{Acknowledgments}

The authors would like to acknowledge the examples of great educators and mentors over the course of their educational careers - Elliot M. Frohman, M.D., Ph.D., Teresa C. Frohman, PA-C, Moronke Oke, Ph.D., Russell Grubbs, Ph.D., Diane Schallert, Ph.D., Toni Falbo, Ph.D., Tina Szopinski, Ph.D., Jon Valla, Ph.D., Mark Wireman, D.C., Val Martinez, Ph.D., Donna Blakeney, M.S., Melissa Trombley, Ph.D., and Nick Schoonover, M.S.

These individuals, while not perfect, embodied the ideal of all education and especially that of medical education - working hard to ensure that we "get it right" for the benefit of ourselves and our patients. Their care, compassion, and dedication to the students in their teaching are shining examples of how medical education can and should move in the near future.

\section{Conflict of Interest}

Thomas C. Varkey: is an Adjunct Professor at Grand Canyon University and receives payment for his teaching and grading, he is a faculty member with the National Multiple Sclerosis Society's Monthly Fellows Difficult Case Discussion Webinar, and Thomas serves on the board of editors for ProClinS Cardiology.

Zachary I. Merhavy: Nothing to disclose. Rhonda M.J. Varkey: Nothing to disclose. Jack B. Ding: Nothing to disclose. John A. Varkey: Nothing to disclose.

\section{Financial Disclosure}

The authors declared no financial support.

\section{References}

[1] Flexner A. Medical education in the United States and Canada. The Carnegie Foundation for the Advancement of Teaching, Bulletin Number Four. 1910. Available from: http://archive.carnegiefoundation.org/publications/ pdfs/elibrary/Carnegie_Flexner_Report.pdf 
[2] Wu JH, Gruppuso PA, Adashi EY. The selfdirected medical student curriculum. JAMA. 2021;326(20):2005-2006. Available from: https://doi.org/10.1001/jama.2021.16312

[3] Duffy TP. The Flexner report - 100 years later. Yale J Biol Med. 2011;84(3):269-276. Available from: https://www.ncbi.nlm.nih.gov/pmc/articles/PMC $3178858 /$

[4] Doctors in the house: History of medical interns and residents at U-M hospitals [Internet]. University of Michigan Health [cited 2022 Jan 3]. Available from: https://www.uofmhealth.org/news/archive/202007/ doctors-house-history-medical-interns-and-residentsu-m

[5] Tsichlis JT, Del Re AM, Carmody JB. The past, present, and future of the United States Medical Licensing Examination Step 2 Clinical Skills Examination. Cureus. 2021;13(8):e17157. Available from: https://doi.org/10.7759/cureus. 17157

[6] Miller G, Benke M, Chaloux B, Schroeder R, Smutz W, Swan K. Leading the e-learning transformation of higher education. Sterling, VA: Stylus Publishing, LLC; 2014. $270 \mathrm{pp}$.

[7] Lieblein E. Critical factors for successful delivery of online programs. The Internet and Higher Education. 2000;3(3):161-174. Available from: https://doi.org/10.1016/S1096-7516(01)00036-7

[8] O'Doherty D, Dromey M, Lougheed J, Hannigan A, Last J, McGrath D. Barriers and solutions to online learning in medical education - an integrative review. BMC Medical Education. 2018;18(1):130. Available from: https://doi.org/10.1186/s12909-018-1240-0

[9] Xu X, Reed M. The impact of internet access on research output - a cross-country study. Information Economics and Policy. 2021;56:100914. Available from: https://doi.org/10.1016/j.infoecopol.2021.100914

[10] Cantillon P, Irish B, Sales D. Using computers for assessment in medicine. BMJ. 2004;329(7466):606-609. Available from: https://doi.org/10.1136/bmj.329.7466.606

[11] Clauser BE, Margolis MJ, Swanson DB. An examination of the contribution of computer-based case simulations to the USMLE Step 3 Examination. Academic Medicine. 2002;77(10):S80-S82.Available from: https://doi.org/10.1097/00001888-20021000100026

[12] Clinical Fellows Complex Case Webinar [Internet]. The National Multiple Sclerosis Society [cited 2022 Jan 3]. Available from: https://www.nationalmssociety.org/ForProfessionals/Clinical-Care/Professional-

Education/Fellows
[13] Ahmed H, Allaf M, Elghazaly H. COVID-19 and medical education. The Lancet Infectious Diseases. 2020;20(7):777-778. Available from: https://doi.org/10.1016/S1473-3099(20)30226-7

[14] Usak M, Masalimova AR, Cherdymova EI, et al. New playmaker in science education: COVID-19. Journal of Baltic Science Education. 2020;19(2):180-185. Available from: https://doi.org/10.33225/jbse/20.19.180

[15] Marinoni G, Van't Land H, Jensen T. The impact of Covid-19 on higher education around the world. IAU Global Survey Report. Paris: International Association of Universities; 2020. Available from: https://www.iauaiu.net/IMG/pdf/iau_covid19_and_he_survey_report_final_may_2020.pdf

[16] TMS Collaborative. The perceived impact of the Covid-19 pandemic on medical student education and training - an international survey. BMC Medical Education. 2021;21:566. Available from: https://doi.org/10.1186/s12909-021-02983-3

[17] Samaraee AA. The impact of the COVID-19 pandemic on medical education. British Journal of Hospital Medicine. 2020;81(7):1-4. Available from: https://doi.org/10.12968/hmed.2020.0191

[18] Sandhu P, de Wolf M. The impact of COVID-19 on the undergraduate medical curriculum. Medical Education Online. 2020;25(1):1764740. Available from: https://doi.org/10.1080/10872981.2020.1764740

[19] Compton S, Sarraf-Yazdi S, Rustandy F, Radha Krishna LK. Medical students' preference for returning to the clinical setting during the COVID-19 pandemic. Medical Education. 2020;54(10):943-950. Available from: https://doi.org/10.1111/medu.14268

[20] Akers A, Blough C, Iyer MS. COVID-19 implications on clinical clerkships and the residency application process for medical students. Cureus. 2020;12(4):e7800. Available from: https://doi.org/10.7759/cureus.7800

[21] Choi B, Jegatheeswaran L, Minocha A, Alhilani M, Nakhoul M, Mutengesa E. The impact of the COVID-19 pandemic on final year medical students in the United Kingdom: a national survey. BMC Medical Education. 2020;20:206. Available from: https://doi.org/10.1186/s12909-020-02117-1

Received: 2022-01-04

Revision Requested: 2022-02-02

Revision Received: 2022-02-05

Accepted: 2022-02-07 